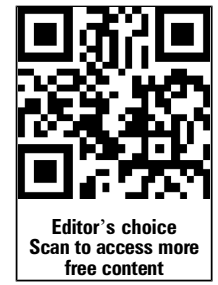

${ }^{1}$ Cellular Pathology Department, University Hospital Southampton NHS Foundation Trust, Southampton, UK ${ }^{2}$ School of Health Sciences and Social Work, University of Portsmouth, Portsmouth, UK

\section{Correspondence to} Joanne Horne, Cellular Pathology Department, South Block, Southampton General Hospital, MP2, Level E, Tremona Road, Southampton, Hampshire S016 6YD, UK joanne.horne@uhs.nhs.uk

Received 15 December 2013 Revised 6 January 2014 Accepted 14 January 2014 Published Online First 3 February 2014
To cite: Horne J, Bateman AC, Carr NJ, et al. J Clin Pathol 2014:67: 383-388.

\title{
Lymph node revealing solutions in colorectal cancer: should they be used routinely?
}

\author{
Joanne Horne, ${ }^{1}$ Adrian C Bateman, ${ }^{1}$ Norman I Carr, ${ }^{1}$ Isobel Ryder ${ }^{2}$
}

\section{ABSTRACT}

The Royal College of Pathologists (RCPath) and College of American Pathologists recommend that at least 12 lymph nodes should be harvested for adequate staging of colorectal carcinoma. Just one nodal tumour deposit upstages the malignancy from pNO to pN1. This is critically important as node-positive patients ( $\mathrm{pN} 1$ ) are considered for adjuvant chemotherapy whereas nodenegative patients ( $\mathrm{pNO}$ ) may not be. It is not always easy to harvest the required number, especially in patients with rectal carcinoma who may have received neoadjuvant therapy —an increasingly common treatment. The use of neoadjuvant therapy is known to further decrease the number and size of identifiable lymph nodes within specimens, meaning that the lymph node harvest often fails to reach RCPath guidelines. Lymph node revealing solutions consisting of either single chemicals such as alcohol or acetone or compounds have been investigated to help improve the lymph node harvest in difficult specimens, for example, those received following neoadjuvant therapy. Published research evidence reviewed here suggests that lymph node revealing solutions significantly improve lymph node harvesting, and that glacial acetic acid, ethanol, water and formalin is advantageous in comparison with other revealing solutions in that it is safe, cheap, easy to use and relatively quick. However, the quantity of good evidence is limited and the clinical implications of improving lymph node harvesting require further research.

\section{INTRODUCTION}

Colorectal carcinoma (CRC) is the fourth most common cancer in the UK. ${ }^{1}$ In 2010 alone, there were 40695 new diagnoses and 16013 deaths from the disease. ${ }^{2}$ High quality histopathological assessment, including harvesting of an adequate number of lymph nodes, is required in order to accurately stage the patient and help deliver the most appropriate treatment postsurgery. The presence of metastases within lymph nodes is inextricably linked to the prognosis of the patient. ${ }^{3}$

Current recommendations are that at least 12 lymph nodes should be retrieved for adequate staging of CRC, ${ }^{4}$ with all mesentery within the tumour vicinity searched. Just one nodal tumour deposit upstages the malignancy from $\mathrm{pN} 0$ to pN1. ${ }^{4}$ This is important as node-positive patients (pN1) are considered for adjuvant chemotherapy whereas node-negative patients ( $\mathrm{pN} 0$ ) may not be. ${ }^{6}$

The requirement for at least 12 lymph nodes is based on evidence demonstrating the prognostic significance of lymph node harvesting. ${ }^{78}$ Some literature suggests that more lymph nodes should be harvested for adequate staging, ${ }^{7}$ but 12 is the current consensus. ${ }^{4} 5$ At our hospital, specimens are resampled when less than 12 lymph nodes are harvested at the first attempt.

Lymph node harvesting is traditionally performed by a manual technique of vision and palpation. In the majority of cases, harvesting a minimum of 12 lymph nodes should be achievable but this may become more difficult in the rectum, especially in patients who have received neoadjuvant chemotherapy as the size of lymph nodes may be reduced, making identification more challenging. ${ }^{9}$ Use of neoadjuvant therapy is not the sole cause of an inadequate lymph node harvest. Other limiting factors are known to be fixation time, ${ }^{3} 10$ experience of the surgeon and failure by the dissector to appropriately examine all nodes within a specimen, either due to lack of experience or poor technique. ${ }^{11} 12$

In response to this, a number of studies have been carried out to address the issue of lymph node harvesting, using a variety of methods. These have included extending the fixation time, ${ }^{3} 1314$ injecting dyes to accurately map lymph node chains, ${ }^{15} 16$ transilluminating the mesentery to identify small nodes, ${ }^{17-22}$ submitting residual mesenteric tissue in its entirety ${ }^{23}$ and using a variety of different lymph node revealing solutions. ${ }^{3}{ }^{17-44}$ In many studies, these techniques have been combined. ${ }^{17-24} 272831-34$

This review is based on a search of medical and scientific databases to identify all available literature written in English, and published within the last 30 years. The review focuses on the use of chemical lymph node revealing solutions in relation to CRC specimens only. Studies related to other carcinoma types are excluded from this review, as are those which use other adjunct techniques such as lymph node mapping. The studies within this review are mainly of cohort and case control design, ${ }^{3}$ 17-44 although there is also one randomised controlled trial. ${ }^{38}$

\section{HISTORY OF LYMPH NODE REVEALING SOLUTIONS}

Since the first fat clearance technique using dye injection and lymph node mapping with alcohol clearance was described by Gilchrist and David ${ }^{24}$ in 1938, authors have studied a variety of lymph node revealing solutions. ${ }^{17-43} \mathrm{~A}$ number of early studies investigated the use of alcohols, acetone and xylene, ${ }^{17-19} 21222628 \quad 30-33$ but since 1997 when the first study was published, ${ }^{41}$ there has been a greater focus on the use of glacial acetic acid, ethanol, water and formalin (GEWF) (table 1). ${ }^{35-42}$ 
Table 1 Number of harvested lymph nodes

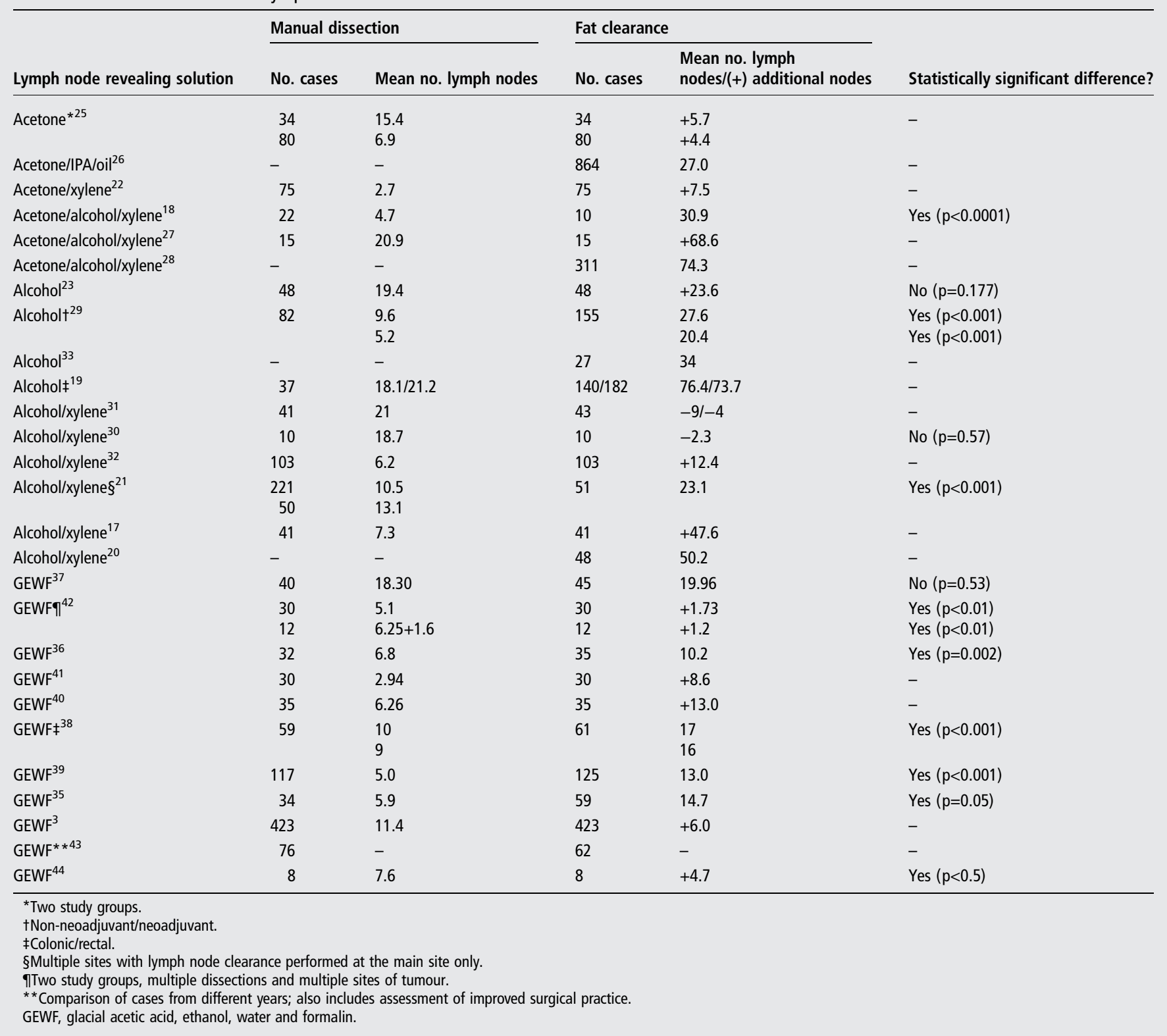

\section{REVIEW OF THE LITERATURE}

\section{Number of lymph nodes retrieved}

The most commonly described benefit of using lymph node revealing solutions is the pure increase in the numbers of lymph nodes harvested, many of which are of a smaller size than might be identified by manual dissection. Studies have shown a variable increase in harvested lymph nodes. In one study, a mean harvest of 76.4 and 73.7 lymph nodes was seen after application of alcohol in colonic and rectal resections, respectively. ${ }^{19}$ In the same study, a secondary manual dissection identified a mean of 18.1 and 21.2 lymph nodes, respectively, but the authors did not clarify whether both sets of dissections were performed by the same individuals. ${ }^{19}$ If manual dissections had been carried out by less experienced individuals then it is possible that this may have also affected the numbers of nodes harvested.

\section{Metastatic incidence and upstaging}

Metastatic incidence refers to the proportion of lymph nodes which contain tumour deposits. A decrease in metastatic incidence after the use of lymph node revealing solutions has been reported. ${ }^{17} 18222527313840-42$ Saleki and Haeri ${ }^{40}$ attributed significance to this finding, stating it to be due to the overall greater number of lymph nodes harvested after secondary dissection. In contrast, five studies showed an increase in metastatic incidence, ${ }^{29} \quad 32 \quad 36 \quad 3739$ but not always with significance. ${ }^{37} 39$

Upstaging refers to an upwards change in pathological staging, which may then alter patient treatment if there is a shift from node-negative ( $\mathrm{pN} 0)$ to node-positive ( $\mathrm{pN} 1$ or $\mathrm{pN} 2)$. This is because node-positive patients receive chemotherapy, while node-negative patients may not. ${ }^{45}$

Nine studies reported upstaging after the use of lymph node revealing solutions, ${ }^{17} 23252731 \quad 32 \quad 40-42$ ranging from $2.4 \%$ to $33 \%$ (table 2). ${ }^{3141}$ Six of these claimed the finding to be significant, in that upstaging from Dukes' B to Dukes' C was reported, prompting adjuvant therapy. ${ }^{17} 2527324041$ However, this may not have been a correct assumption because most of these studies had questionable underlying primary manual dissection 
practice with fewer than the recommended minimum of 12 lymph nodes found on average (range 2.94-7.3). ${ }^{17} 25324041$ These studies were therefore more likely to identify upstaging once a lymph node revealing solution had been applied. It is likely that upstaging would have been insignificant, or not present at all, had there been optimal primary manual dissection. In one study by Koren et $a l^{41}$ there was upstaging in 10 cases, and a further eight cases had the staging changed from $\mathrm{Nx}$ to $\mathrm{N} 0$, suggesting an underlying deficit in primary manual dissection technique. The case upstaged by Brown et $a l^{27}$ was a soft tissue metastasis which the authors suggested may have been artefactual. The evidence in the literature is therefore questionable.

\section{Does lymph node size matter?}

Multiple studies have demonstrated smaller sized lymph nodes after lymph node revealing solutions are used (table 3). ${ }^{3} 18 \quad 192225 \quad 3639404244$ Some of the more recent studies using GEWF have assessed and attributed statistical significance to this. ${ }^{36} 394042$ Brown et al ${ }^{27}$ found that $83 \%$ of additional lymph nodes were $\leq 2 \mathrm{~mm}$ in size. Where GEWF is used this may be due to the white colour of lymph nodes which facilitates detection. ${ }^{39}$ There is ongoing debate regarding the clinical significance of CRC metastases in small lymph nodes. Dhar et $a^{46}$ concluded that metastatic lymph node size is a strong prognostic variable in CRC, using two sample log rank testing to demonstrate that the prognostic impact decreased when lymph nodes were more than $10 \mathrm{~mm}$ in diameter. Dhar et $a l^{46}$ did concede that their findings needed to be confirmed with a larger study before clinical application. In another recent study, Märkl et al concluded that 'minute lymph nodes [ $<1 \mathrm{~mm}]$ have virtually no role in correct histopathological lymph node staging. ${ }^{47}$ They did however agree that the detection of relatively small lymph nodes $(1-5 \mathrm{~mm}$ ) was an important factor for exact lymph node staging and was prognostically

Table 2 Incidence of upstaging

\begin{tabular}{|c|c|}
\hline $\begin{array}{l}\text { Lymph node revealing } \\
\text { solution }\end{array}$ & Findings \\
\hline Acetone $\mathrm{e}^{25}$ & $\begin{array}{l}2 / 34(5.9 \%) \text { upstaged from } \mathrm{pN} 1 \text { to } \mathrm{pN} 2 * \\
2 / 80(2.5 \%) \text { upstagedt: } \\
1 \text { upstaged from pN0 to } \mathrm{pN} 1 \\
1 \text { upstaged from } \mathrm{pN} 1 \text { to } \mathrm{pN} 2\end{array}$ \\
\hline Alcohol and xylene ${ }^{17}$ & $\begin{array}{l}3 / 41(7.3 \%) \text { cases upstaged from Dukes' B to } \\
\text { Dukes' C }\end{array}$ \\
\hline GEWF $^{41}$ & $\begin{array}{l}10 / 30(33 \%) \text { upstaged } \neq: \\
4 \text { upstaged from Nx to N1 } \\
4 \text { upstaged from N0 to N1 } \\
2 \text { upstaged from N1 to N2 }\end{array}$ \\
\hline GEWF $^{42}$ & $\begin{array}{l}4 / 30(13.0 \%) \text { upstaged-no colorectal cancer } \\
\text { cases upstaged§ }\end{array}$ \\
\hline Alcohol and xylene $\mathrm{e}^{32}$ & $5 / 58(8.6 \%)$ upstaged (Dukes' B to Dukes' C) \\
\hline GEWF $^{40}$ & $3 / 35(8.6 \%)$ upstaged from Dukes' B to Dukes' C \\
\hline $\begin{array}{l}\text { Acetone, alcohol and } \\
\text { xylene }^{27}\end{array}$ & $\begin{array}{l}4 / 15 \text { (26.7\%) upstaged: } \\
1 \text { upstaged from pN0 to } p N 1 \\
3 \text { upstaged from pN1 to } p N 2\end{array}$ \\
\hline Alcohol and $x y l e n e^{31}$ & Stage changed in $2 / 84(2.4 \%)$ of cases \\
\hline Alcohol $^{23}$ & $2 / 10(20.0 \%)$ upstaged from $\mathrm{pN} 1$ to $\mathrm{pN} 2$ \\
\hline
\end{tabular}

relevant, with an association between a high number of harvested lymph nodes and a favourable outcome in colon carcinoma. ${ }^{47}$

It is important to consider whether finding a greater number of smaller lymph nodes has the potential to change patient management. If the only significant finding is a greater number of smaller tumour-free lymph nodes, then the patient will remain node-negative and there will be no change in treatment. There will be no benefit to the patient but there will be a cost to the laboratory, both in terms of increased turnaround times and finances.

If metastases are prevalent in larger lymph nodes (ie, $>5 \mathrm{~mm}$ ), then they should be identified by manual dissection, providing the dissector is adequately experienced. If this is the case, then one might argue that the use of lymph node revealing solutions is not necessary. It may be that education is as important a tool as is the use of adjunct chemicals, but currently there remains a lack of evidence to prove or disprove this.

\section{CHALLENGES IN STUDY DESIGN Quality of evidence}

The greatest challenge in assessing the true value of lymph node revealing solutions in CRC surrounds the quality of the existing evidence. The majority of existing studies are open to at least one type of bias which may invalidate the conclusions. Different types of bias which may have affected the existing studies are summarised in box 1 .

\section{Underlying primary dissection practice}

Many of the studies did not achieve the recommended targets during primary manual dissection, ${ }^{17} 2225293235363839-42$ with the mean number of lymph nodes harvested ranging from $2.7^{22}$ to $21.2 .{ }^{19}$ Kelder $e t a l^{39}$ only found a mean of 5.0 lymph nodes by primary manual dissection in 117 colonic specimens, even though their study was relatively recent. The highest number of lymph nodes found in any specimen in their study was only 17, ${ }^{39}$ which was lower than the average number found by primary manual dissection in a number of other studies. ${ }^{19} 23273037$ In the study by Schmitz-Moormann et al, ${ }^{22}$ routine primary dissection yielded a mean nodal count of 2.7 , and failed to identify any nodes in six out of the 75 cases. This issue is supported by a number of studies where the importance of enthusiasm and skill of both pathologist and surgeon is noted because it directly affects the quality of the specimen and subsequent nodal harvest. ${ }^{18} 3542$ Gregurek and $\mathrm{Wu}^{37}$ found that educating pathologists in appropriate primary manual dissection practice gave more powerful results than the use of lymph node revealing solutions; however, there was potential bias in their study (box 1). Additionally, failing to consider the experience of dissectors may also introduce sampling bias, perhaps via the involvement of inexperienced dissectors who might miss smaller lymph nodes in comparison with dissectors who are highly experienced in manual dissection. It was often unclear in the case control studies who performed the secondary dissection. ${ }^{17-24} \quad 26-29 \quad 31-43$ The exceptions to this were the studies by Jass et $a l^{30}$ and Vogel et $a l,{ }^{25}$ where secondary dissection was performed by the first author or one of three pathologists not aware of the outcome of the primary dissection, respectively. Only one of the studies included true randomisation of specimens into study groups. ${ }^{38}$ Gregurek and $\mathrm{Wu}^{37}$ claimed that cases were alternately enrolled into study and control groups; however, pathologists were given the opportunity to change this, which weakened their study design. 
Table 3 The effect of lymph node revealing solutions on the size of lymph nodes

\begin{tabular}{|c|c|c|c|}
\hline $\begin{array}{l}\text { Lymph node revealing } \\
\text { solution }\end{array}$ & Control group & Study group & $\begin{array}{l}\text { Statistically significant } \\
\text { difference? }\end{array}$ \\
\hline Acetone $^{25}$ & Average diameter $2.7 \mathrm{~mm}$ & Average diameter $2.0 \mathrm{~mm}$ & - \\
\hline Acetone, IPA and oil ${ }^{26}$ & - & - & - \\
\hline Acetone and xylene $\mathrm{e}^{22}$ & $\begin{array}{l}9.7 \% \text { nodes } \leq 2 \mathrm{~mm}, \\
10 \% \text { metastatic nodes } \leq 2 \mathrm{~mm}\end{array}$ & $\begin{array}{l}83.6 \% \text { nodes } \leq 2 \mathrm{~mm} \\
0.6 \% \text { metastatic nodes } \leq 2 \mathrm{~mm}\end{array}$ & - \\
\hline $\begin{array}{l}\text { Acetone, alcohol and } \\
\text { xylene }^{18}\end{array}$ & $\begin{array}{l}4.8 \% \text { nodes }<5 \mathrm{~mm} \\
100 \% \text { metastatic nodes }>5 \mathrm{~mm}\end{array}$ & $\begin{array}{l}89 \% \text { nodes }<5 \mathrm{~mm} \\
40 \% \text { metastatic nodes }<5 \mathrm{~mm}\end{array}$ & - \\
\hline $\begin{array}{l}\text { Acetone, alcohol and } \\
\text { xylene }^{27}\end{array}$ & - & $\begin{array}{l}50 \% \text { nodes }<1 \mathrm{~mm} \\
82 \% \text { nodes }<2 \mathrm{~mm} \\
83 \% \text { metastatic nodes }<3 \mathrm{~mm} \\
\text { In both groups, } 75 \% \text { metastatic nodes }<2 \mathrm{~mm}\end{array}$ & - \\
\hline $\begin{array}{l}\text { Acetone, alcohol and } \\
\text { xylene }^{28}\end{array}$ & - & - & - \\
\hline Alcohol $^{23}$ & - & $\begin{array}{l}88.6 \% \text { nodes } \leq 2 \mathrm{~mm} \\
78.6 \% \text { metastatic nodes } \leq 2 \mathrm{~mm}\end{array}$ & - \\
\hline Alcohol $^{29}$ & - & - & - \\
\hline Alcohol $^{33}$ & - & $\begin{array}{l}75.5 \% \text { metastatic nodes }<5 \mathrm{~mm} \\
24.5 \% \text { metastatic nodes }>5 \mathrm{~mm}\end{array}$ & - \\
\hline Alcohol $^{19}$ & $\begin{array}{l}49.5 \% \text { nodes }<4 \mathrm{~mm} \\
14.8 \% \text { metastatic nodes }<4 \mathrm{~mm}\end{array}$ & $\begin{array}{l}77.9 \% \text { nodes }<4 \mathrm{~mm} \\
32.6 \% \text { metastatic nodes }<4 \mathrm{~mm}\end{array}$ & - \\
\hline Alcohol and xylene $e^{31}$ & - & - & - \\
\hline Alcohol and xylene ${ }^{32}$ & - & - & - \\
\hline Alcohol and xylene ${ }^{21}$ & - & - & - \\
\hline Alcohol and xylene ${ }^{17}$ & - & $\begin{array}{l}77 \% \text { of metastatic nodes } \leq 5 \mathrm{~mm} \\
\text { In } 7 \text { cases metastases only found in nodes } \leq 5 \mathrm{~mm}\end{array}$ & - \\
\hline Alcohol and xylene $\mathrm{e}^{20}$ & - & $\begin{array}{l}94 \% \text { nodes } \leq 5 \mathrm{~mm} \\
6 \% \text { nodes }>6 \mathrm{~mm} \\
71.8 \% \text { metastatic nodes } \leq 5 \mathrm{~mm}\end{array}$ & - \\
\hline GEWF $^{42}$ & Mean diameter $6.8 \mathrm{~mm}( \pm 4.13)$ & Mean diameter $4.2 \mathrm{~mm}( \pm 3.46)$ & Yes $(p<0.01)$ \\
\hline GEWF $^{36}$ & $\begin{array}{l}\text { Average diameter of metastatic nodes } 7 \mathrm{~mm} \\
( \pm 4 \mathrm{~mm}) \\
41 \% \text { nodes } \leq 5 \mathrm{~mm}\end{array}$ & $\begin{array}{l}\text { Average diameter of metastatic nodes } 5 \mathrm{~mm}( \pm 2 \mathrm{~mm}) \\
60 \% \text { nodes } \leq 5 \mathrm{~mm}\end{array}$ & Yes $(0.046)$ \\
\hline GEWF $^{41}$ & - & Diameter $0.5-7.0 \mathrm{~mm}$ & - \\
\hline GEWF $^{40}$ & $\begin{array}{l}\text { Mean diameter } 0.429 \mathrm{~mm} \text { (minimum } 0.1 \mathrm{~mm} \text { ) } \\
\text { All nodes }>0.9 \mathrm{~mm} \text { identified by standard } \\
\text { technique } \\
\text { Mean diameter metastatic nodes } 0.568 \mathrm{~mm} \\
26 \% \text { nodes }<5 \mathrm{~mm} \text { identified by standard } \\
\text { practice } \\
55.3 \% \text { metastatic nodes } \leq 5 \mathrm{~mm}\end{array}$ & $\begin{array}{l}\text { Mean diameter } 0.268 \mathrm{~mm}(0.2-0.9 \mathrm{~mm}) \\
\text { Mean diameter metastatic nodes } 0.35 \mathrm{~mm}\end{array}$ & Yes $(p<0.000001)$ \\
\hline GEWF $^{39}$ & $\begin{array}{l}\text { Median diameter non-metastatic nodes } 6 \mathrm{~mm} \\
\text { Median diameter metastatic nodes } 9 \mathrm{~mm}\end{array}$ & $\begin{array}{l}\text { Median diameter non-metastatic nodes } 4 \mathrm{~mm} \\
\text { Median diameter metastatic nodes } 6 \mathrm{~mm}\end{array}$ & $\begin{array}{l}\text { Yes }(p<0.001) \\
\text { Yes }(p<0.001)\end{array}$ \\
\hline GEWF $^{* 35}$ & - & $\begin{array}{l}86 \% \text { nodes }(246 / 286)<3 \mathrm{~mm} \\
11.5 \% \text { nodes }(33 / 286) 3-6 \mathrm{~mm} \\
1.4 \% \text { nodes }(4 / 286)>6 \mathrm{~mm} \\
6 \text { metastatic nodes }<3 \mathrm{~mm} \text { ( } 5 \text { from neoadjuvant } \\
\text { therapy cases) }\end{array}$ & - \\
\hline GEWF $^{3}$ & Mean diameter $4.3 \mathrm{~mm}$ & Mean diameter $2.5 \mathrm{~mm}$ & - \\
\hline GEWF $^{44}$ & Mean diameter $2.6 \mathrm{~mm}(1-15 \mathrm{~mm})$ & Mean diameter $2.1 \mathrm{~mm}(1-4 \mathrm{~mm})$ & No $(p>0.11)$ \\
\hline
\end{tabular}

\section{Blinding}

Studies involving GEWF will always have an immediate detection bias, caused by an inability to use blinding. Iversen et $a l^{38}$ described GEWF as having 'its own characteristic macroscopic appearance, which is impossible to hide'. This could then either consciously or unconsciously give dissectors the ability to alter their practice which could skew any potentially significant findings. Newell et $a l^{36}$ admit to this limitation, commenting that 'those pathologists using the standard technique would likely examine pericolic fat more thoroughly'.

\section{Time and cost}

The most rapid treatments took $6 \mathrm{~h}$ to complete and all used GEWF. $^{40-42}$ In contrast, the longest treatment using a combination of alcohol and xylene took a minimum of 3 weeks. ${ }^{32}$ Unsurprisingly, many of the more lengthy treatments have been associated with multistep studies, where more than one chemical has been used in the lymph node revealing solution. ${ }^{27} 28 \quad 32$ Many studies taking a day or less of additional time to harvest lymph nodes used GEWF. ${ }^{35-38}{ }^{40-42}$ With the need to modernise National Health Service (NHS) histopathology departments, ${ }^{48-51}$ it is unsurprising that focus appears to be 


\section{Box 1 Types of bias within the literature}

- Anatomical variation in numbers of lymph nodes within the colorectum $^{17} 1920232526283234 \quad 36-38$ 40-42

- Suboptimal underlying manual dissection practice 31722252932353638 39-42

- Inappropriate or unclear sample size 1720272930333744

- Unclear or unbalanced study groups ${ }^{17-19} 222325294042$

- No sample size calculation ${ }^{19} 2225272830313337394044$

- Exclusion criteria unclear or absent ${ }^{17} 3638$

- No randomisation used/strategy unclear 222327313235

- Inability to use blinding 22353638

- No statistics used or described 31722253133

- Statistics used but methods not defined or discussed ${ }^{40}$

- Intervention and comparison compared during different study periods 2937

- Unclear or varying fixation time 29 35-37

- Unclear length of time in lymph node revealing solution ${ }^{39}$

- Lengthy/unclear timescale of study 2227

- Staff allowed to choose which technique to use $\mathrm{s}^{37}$

shifting towards GEWF, which acts as a fixative while also clearing fat in a shorter period of time than other lymph node revealing solutions. In the 21 st century, focusing on lengthy techniques cannot be justified. ${ }^{48-51}$ Even if lengthy multistep techniques are deemed to provide significant findings, it would be inappropriate to substantially delay reporting. In order to maintain and improve turnaround times, a quicker and more effective method of fat clearance is required if it is to be used routinely. As well as adding a diagnostic delay, older lymph node revealing solutions are also said to be expensive. ${ }^{42}$

\section{Toxicity}

Many older studies used noxious substances, most notably the aromatic hydrocarbon xylene. ${ }^{17-22} 28 \quad 30-34$ Xylene was once ubiquitous in histopathology laboratories as a clearing agent used routinely in processing and staining. Laboratories are now seeking to eliminate the use of xylene in processing, ${ }^{52-54}$ due to its known carcinogenic potential. ${ }^{52}$ This has been facilitated by the introduction of xylene-free processing technology. ${ }^{55} 56$ As a result of this, only one study in the last 10 years has included xylene. ${ }^{27}$ In contrast, there have been a number of recent studies assessing the use of GEWF, which is seen as a better lymph node revealing solution than its predecessors because it is safe, cheap, easy to prepare and handle, $3353638-414344$ odourless, can be used with standard ventilation, and has no adverse effect on routine special stains or immunohistochemistry. ${ }^{36}$

\section{CONCLUSIONS}

As yet, there is no clear evidence to indicate whether one lymph node revealing solution is better than another from the current literature; however, the use of carcinogenic chemicals is inappropriate in terms of health and safety. ${ }^{17-22} \quad 25-28 \quad 30-34$ Lengthy lymph node revealing techniques which add significant reporting delays ${ }^{19} 27 \quad 28 \quad 32$ are inappropriate in a modern NHS. ${ }^{48-51}$ A number of studies have claimed that GEWF is a safe and efficient lymph node revealing solution, ${ }^{19}$ 36-42 which is quick, cheap, easy to prepare and handle. ${ }^{18} 3941$ In their prospective case control study, Ustün $e a^{42}$ stated that historical fat clearance techniques were difficult to handle and expensive while GEWF was easier to use with better results. GEWF could be further investigated with appropriately designed studies, adopting randomisation of cases and minimisation of any potential bias which has been an issue in the existing literature. It is difficult to determine whether the use of GEWF or any other lymph node revealing solution leads to upstaging from nodenegative to node-positive; bias in existing studies limits their conclusions. Until evidence can show that the use of lymph node revealing solutions significantly affects patient management, their routine use cannot be recommended as no benefit to the patient has yet been proven. The next steps should be to design appropriate studies in order to look for statistically significant differences in lymph node harvest associated with the use of these solutions. This would help to test the hypothesis that the use of lymph node revealing solutions contributes to patient management and would ensure that the most appropriate evidence-based treatment options are available to patients.

\section{Take home messages}

- The use of lymph node revealing solutions leads to a significant increase in the number of harvested lymph nodes in colorectal carcinoma resection specimens.

- The use of lymph node revealing solutions leads to detection of significantly smaller lymph nodes and may lead to upstaging, which can change patient management by prompting adjuvant therapy. It has yet to be shown whether these findings have any clinical significance and therefore whether they can enhance patient management.

- Glacial acetic acid, ethanol, water and formalin is a safe and efficient lymph node revealing solution and its potential utility should be investigated further. Other older lymph node revealing solutions such as xylene have cost implications - in terms of finance, turnaround times and health effects; therefore, studies of their use are no longer relevant to modern practice.

Acknowledgements The authors are grateful to Dr Garry Dix for his comments on the final formatting of the manuscript.

Contributors The concept for this review was created by JH and IR. JH prepared the first draft of the script. ACB, NJC and IR contributed to the script and agreed on the final version

Competing interests The research required during the preparation of this script also formed part of a body of work leading to the submission of a Professional Doctorate thesis by JH.

Provenance and peer review Not commissioned; externally peer reviewed.

\section{REFERENCES}

1 Cancer Research UK. Bowel cancer key facts. http://www.cancerresearchuk.org/ cancer-info/cancerstats/keyfacts/bowel-cancer/ (accessed Dec 2013).

2 Cancer Research UK. Bowel cancer statistics. http://www.cancerresearchuk.org/ cancer-info/cancerstats/types/bowel/?script=true (accessed Dec 2013).

3 Lindboe CF. Lymph node harvest in colorectal adenocarcinoma specimens: the impact of improved fixation and examination procedures. APMIS 2011;119:347-55.

4 Williams GT, Quirke P, Shepherd NA. Dataset for colorectal cancer. 2nd edn. London: Royal College of Pathologists, 2007.

5 Compton CC, Fielding LP, Burgart LJ, et al. Prognostic factors in colorectal cancer: College of American Pathologists consensus statement 1999. Arch Pathol Lab Med 1999;124:979-94.

6 Sommariva A, Donisi PM, Gnocato B, et al. Factors affecting false-negative rates on ex vivo sentinel lymph node mapping in colorectal cancer. Eur J Surg Oncol 2010:36:130-4 
7 Tsai $\mathrm{HL}$, Lu CY, Hsieh JS, et al. The prognostic significance of total lymph node harvest in patients with T2-4N0M0 colorectal cancer. J Gastrointest Surg 2007;11:660-5.

8 Wong SL, Ji H, Hollenbeck BK, et al. Hospital lymph node examination rates and survival after resection for colon cancer. JAMA 2007:298:2149-54.

9 Marks JH, Valsdottir EB, Rather AA, et al. Fewer than 12 lymph nodes can be expected in a surgical specimen after high-dose chemoradiation therapy for rectal cancer. Dis Colon Rectum 2010;53:1023-9.

10 van Steenbergen $L N$, van Lijnschoten $\mathrm{G}$, Rutten $\mathrm{HJ}$, et al. Improving lymph node detection in colon cancer in community hospitals and their pathology department in southern Netherlands. Eur J Surg Oncol 2009;36:135-40.

11 Sanders SA, Smith A, Carr RA, et al. Enhanced biomedical scientist cut-up role in colonic cancer reporting. J Clin Pathol 2012;65:517-21.

12 Chen SL, Bilchik AJ. More extensive nodal dissection improves survival for stages I to III of colon cancer: a population-based study. Ann Surg 2006;244:602-10.

13 Greco P, Andreola S, Magro G, et al. Potential pathological understaging of pT3 rectal cancer with less than 26 lymph nodes recovered: a prospective study based on a resampling of 50 rectal specimens. Virchows Arch 2006;449:647-51.

14 Poller DN. Method of specimen fixation and pathological dissection of colorectal cancer influences retrieval of lymph nodes and tumour nodal stage. Eur J Surg Oncol 2000:26:758-62

15 Märkl B, Kerwel T, Jähnig $H$, et al. Lymph node preparation in colorectal cancer. Ex vivo methylene blue injection as a novel technique to improve lymph node visualization. Pathologe 2008;29:274-9.

16 Kerwel TG, Spatz J, Anthuber $M$, et al. Injecting methylene blue into the inferior mesenteric artery assures an adequate lymph node harvest and eliminates pathologist variability in nodal staging for rectal cancer. Dis Colon Rectum 2009;52:935-41.

17 Haboubi NY, Clark P, Kaftan SM, et al. The importance of combining xylene clearance and immunohistochemistry in the accurate staging of colorectal carcinoma. J $R$ Soc Med 1992;85:386-8.

18 Sanchez W, Luna-Perez P, Alvarado I, et al. Modified clearing technique to identify lymph node metastases in post-irradiated surgical specimens from rectal adenocarcinomas. Arch Med Res 1996:27:31-6.

19 Hida J, Mori N, Kubo R, et al. Metastases from carcinoma of the colon and rectum detected in small lymph nodes by the clearing method. J Am Coll Surg 1994;178:223-8

20 Haboubi NY, Abdalla SA, Amini S, et al. The novel combination of fat clearance and immunohistochemistry improves prediction of the outcome of patients with colorectal carcinomas: a preliminary study. Int J Colorect Dis 1998;13:99-102.

21 Cawthorn SJ, Gibbs NM, Marks CG. Clearance technique for the detection of lymph nodes in colorectal cancer. Br J Surg 1986;73:58-60.

22 Schmitz-Moormann P, Thomas C, Pohl C, et al. Patho-anatomical demonstration of lymph node metastases in a surgical specimen. Path Res Pract 1982;174:403-11.

$23 \mathrm{Kim}$ YM, Suh $\mathrm{JH}$, Cha $\mathrm{HJ}$, et al. Additional lymph node examination from entire submission of residual mesenteric tissue in colorectal cancer specimens may not add clinical and pathologic relevance. Hum Pathol 2007;38:762-7.

24 Gilchrist R, David V. Lymphatic spread of carcinoma of the rectum. Ann Surg 1938; 108:621-42.

25 Vogel C, Kirtil T, Oellig F, et al. Lymph node preparation in resected colorectal carcinoma specimens employing the acetone clearing method. Pathol Res Pract 2008;204:11-15.

26 Hyder JW, Talbott TM, Maycroft TC. A critical review of chemical lymph node clearance and staging of colon and rectal cancer at Ferguson Hospital, 1977 to 1982. Dis Colon Rectum 1990:33:923-6.

27 Brown HG, Luckasevic TM, Medich DS, et al. Efficacy of manual dissection of lymph nodes in colon cancer resections. Mod Pathol 2004:17:402-6.

28 Morikawa E, Yasutomi M, Shindou K, et al. Distribution of metastatic lymph nodes in colorectal cancer by the modified clearing method. Dis Colon Rectum 1994:37:219-23.

29 Wang H, Safar B, Wexner SD, et al. The clinical significance of fat clearance lymph node harvest for invasive rectal adenocarcinoma following neoadjuvant therapy. Dis Colon Rectum 2009;52:1767-73.

30 Jass JR, Miller $\mathrm{K}$, Northover JMA. Fat clearance method versus manual dissection of lymph nodes in specimens of rectal cancer. Int J Colorect Dis 1986;1:155-6.

31 Cohen SM, Wexner SD, Schmitt SL, et al. Effect of xylene clearance of mesenteric fat on harvest of lymph nodes after colonic resection. Eur J Surg 1994;160:693-7.
32 Scott KW, Grace RH. Detection of lymph node metastases in colorectal carcinoma before and after fat clearance. Br J Surg 1989;76:1165-7.

33 Herrera L, Villarreal JR. Incidence of metastases from rectal adenocarcinoma in small lymph nodes detected by a clearing technique. Dis Colon Rectum 1992; 35:783-8.

34 Scott KWM, Grace RH, Gibbons P. Five-year follow up study of the fat clearance technique in colorectal carcinoma. Dis Colon Rectum 1994:37:126-8.

35 Svec A, Horák L, Novotný J, et al. Re-fixation in a lymph node revealing solution is a powerful method for identifying lymph nodes in colorectal resection specimens. EJSO 2006:32:426-9.

36 Newell KJ, Sawka BW, Rudrick BF, et al. GEWF solution-an inexpensive, simple and effective aid for the retrieval of lymph nodes from colorectal cancer resections. Arch Pathol Lab Med 2001;125:642-5.

37 Gregurek SF, Her-Juing Wu H. Can GEWF solution improve the retrieval of lymph nodes from colorectal cancer resections? Arch Pathol Lab Med 2009;133:83-6.

38 Iversen LH, Laurberg S, Hagemann-Madsen R, et al. Increased lymph node harvest from colorectal cancer resections using GEWF solution: a randomised study. J Clin Pathol 2008:61:1203-8.

39 Kelder W, Inberg B, Plukker JTM, et al. Effect of modified Davidson's fixative on examined number of lymph nodes and TNM-stage in colon carcinoma. EJSO 2008;34:525-30.

40 Saleki S, Haeri H. Lymph node revealing solution: a prospective study on 35 patients with colorectal carcinomas. Acta Medica Iranica 2002:40:223-5.

41 Koren $\mathrm{R}$, Siegal A, Klein B, et al. Lymph node-revealing solution: simple new method for detecting minute lymph nodes in colon carcinoma. Dis Colon Rectum 1997:40:407-10

42 Ustün MO, Onal B, Tuğyan N, et al. Lymph node revealing solution: is it effective on detecting minute lymph nodes? Adv Clin Path 1999;3:135-8.

43 Storli K, Søndenaa K, Furnes B, et al. Improved lymph node harvest from resected colon cancer specimens did not cause upstaging from TNM stage II to III. World J Surg 2011;35:2796-803.

44 Tasi CK, Chen CY, Liu CY, et al. Reliability and effectiveness of GEWF solution in the identification of lymph nodes in specimens of colorectal carcinoma. Int J Surg Pathol 2012:20:589-95.

45 National Institute for Health and Clinical Excellence. Colorectal cancer: The diagnosis and management of colorectal cancer. http://publications.nice.org.uk/ colorectal-cancer-cg131/guidance (accessed Dec 2013).

46 Dhar DK, Yoshimura $\mathrm{H}$, Kinukawa N, et al. Metastatic lymph node size and colorectal cancer prognosis. J Am Coll Surg 2005;200:20-8.

47 Märkl B, Rößle J, Arnholdt HM, et al. The clinical significance of lymph node size in colon cancer. Mod Pathol 2012;25:1413-22.

48 Department of Health. Report of the Review of NHS Pathology Services in England. http://collections.europarchive.org/tna/20081105144224/http://www.thecarterreview. com/downloads/CarterReviewPathologyReport.pdf (accessed Dec 2013).

49 The Royal College of Pathologists. Key Performance Indicators in Histopathology. http://www.rcpath.org/Resources/RCPath/Migrated\%20Resources/Documents/K/key_ performance_indicators_in_pathology_3_2.pdf (accessed Dec 2013).

50 NHS improvement. Improving histopathology management: 7-day turnaround time. http://www.improvement.nhs.uk/qipp/MenuLevel1/Diagnosis/Pathology/ Histopathology.aspx (accessed Dec 2013).

51 Department of Health. Report of the Second Phase of the Review of NHS Pathology Services in England. http://webarchive.nationalarchives.gov.uk/20130107105354/ http://www.dh.gov.uk/prod_consum_dh/groups/dh_digitalassets/@dh/@en/ documents/digitalasset/dh 091984.pdf (accessed Dec 2013).

52 Buesa RJ, Peshkov M. Histology without xylene. Ann Diagn Pathol 2009:13:246-56

53 Falkeholm L, Grant CA, Magnusson A, et al. Xylene-free method for histological preparation: a multicentre evaluation. Lab Invest 2001;81:1213-21.

54 Ofusori DA, Ayoka AO, Adeeyo OA, et al. Mixture of kerosene and xylene: a contribution to clearing agents. Int J Morphol 2009;27:211-18.

55 Leica Microsystems. Rapid tissue processor Leica Peloris. http://www. leica-microsystems.com/products/total-histology/tissue-processing/details/product/ leica-peloris/ (accessed Dec 2013)

56 Thermo Fisher Scientific Inc. Excelsior ES tissue processor. http://www. thermoscientific.com/en/product/excelsior-es-tissue-processor.html (accessed Dec 2013) 